\title{
COVID-19 in Pakistan: Current Scenario and Future Perspective
}

\author{
Naveed Akhtar ${ }^{*}$
}

${ }^{1}$ Department of Zoology,
Government Postgraduate College
Pattoki (Kasur), Pakistan

\section{Correspondence:}

Naveed Akhtar

Address: Department of Zoology, Government Postgraduate College Pattoki (Kasur), Pakistan

Email:

coordinator.concordiakkc@gmail.com

Received: 14.05.2020,

Accepted: 13.06 .2020

https://doi.org/10.29333/jcei/8354

\begin{abstract}
In developing countries, emergences of the infectious diseases cause serious issues to public health security due to lack of sufficient resources. The emergence of the COVID-2019 in China during late December 2019 resulted in international health emergency all over the world in few weeks and attained high risk category. On 11 March 2020, World Health Organization declared Coronavirus disease as pandemic. Staring from Wuhan, China, coronavirus disease has spread in 209 countries including Pakistan. Till March 30, 2020, the number of causalities by Coronavirus disease has reached up to 33,983 among 722664 confirmed cases affected by this globally. In Pakistan, the first case of the Coronavirus is reported on February 25, 2020 and till 30 March 2020, 1526 confirmed cases and 13 deaths are reported by Ministry of National Health Services of Pakistan. The fight of Pakistan against coronavirus disease like other developing countries may be different from technologically equipped countries. Despite of the limited recourses, Pakistan has taken meticulous measures by developing special hospitals on pattern of Republic of China, availability of rapid diagnosis, strict implementation of lockdown and strong awareness campaign against COVID-19. This article reviews recent outbreak of COVID-19 and its trends of control measures taken by Government of Pakistan for development of nimble health care setup in the country.
\end{abstract}

Keywords: COVID-19, quarantine, vaccination, prevention

\section{INTRODUCTION}

From last two decades, humans are facing third outbreak of corona virus with many clinical manifestations especially fever, pneumonia and other reparatory disorders [1-2]. It includes Middle East Respiratory Syndrome Coronavirus (MERS$\mathrm{CoV})$ and Severe Acute Respiratory Syndrome coronavirus (SARS-CoV) [3]. The year 2019 again ends with another outbreak of coronavirus disease (COVID19) in Wuhan, China, as endemic infection which soon becomes pandemic with rapid transmission rate all over the world. The outbreak was first reported when the Chinese health official reported several cases of acute respiratory syndrome at the end of the December 2019 in Wuhan and other cities of the Republic of China on 8 December 2020 [4-5]. On 31 December 2019, World Health Organization country office in Republic of China was informed about pneumonia of unknown etiology which later on declared as a novel coronavirus disease (COVID-19) and causative agent was declared as Severe Acute Respiratory Syndrome Coronavirus 2 (SARS-CoV-2) [6]. It was initially expressed as pneumonia of unknown origin creating serious health hazards with global implications [7-9]. The outbreak in China is believed to be zoonatic starting from local wet sea food and wild market of Wuhan City, Hubei, China [1011]. First two months of the epidemic of COVID-19 covered significant holidays i.e., New Year Day and Lantern Festival which resulting in rapid spread of the infection. Center for Disease control in Hubei Province provided day by day information of the epidemic from 8 December 2020 to 21 January 2020. Due to increasing impacts, COVID-19 was included under Public Health International Emergency category on January 30, 2020 [12-13]. A fact finding mission of World Health Organization in China estimated that COVID-19 epidemic 


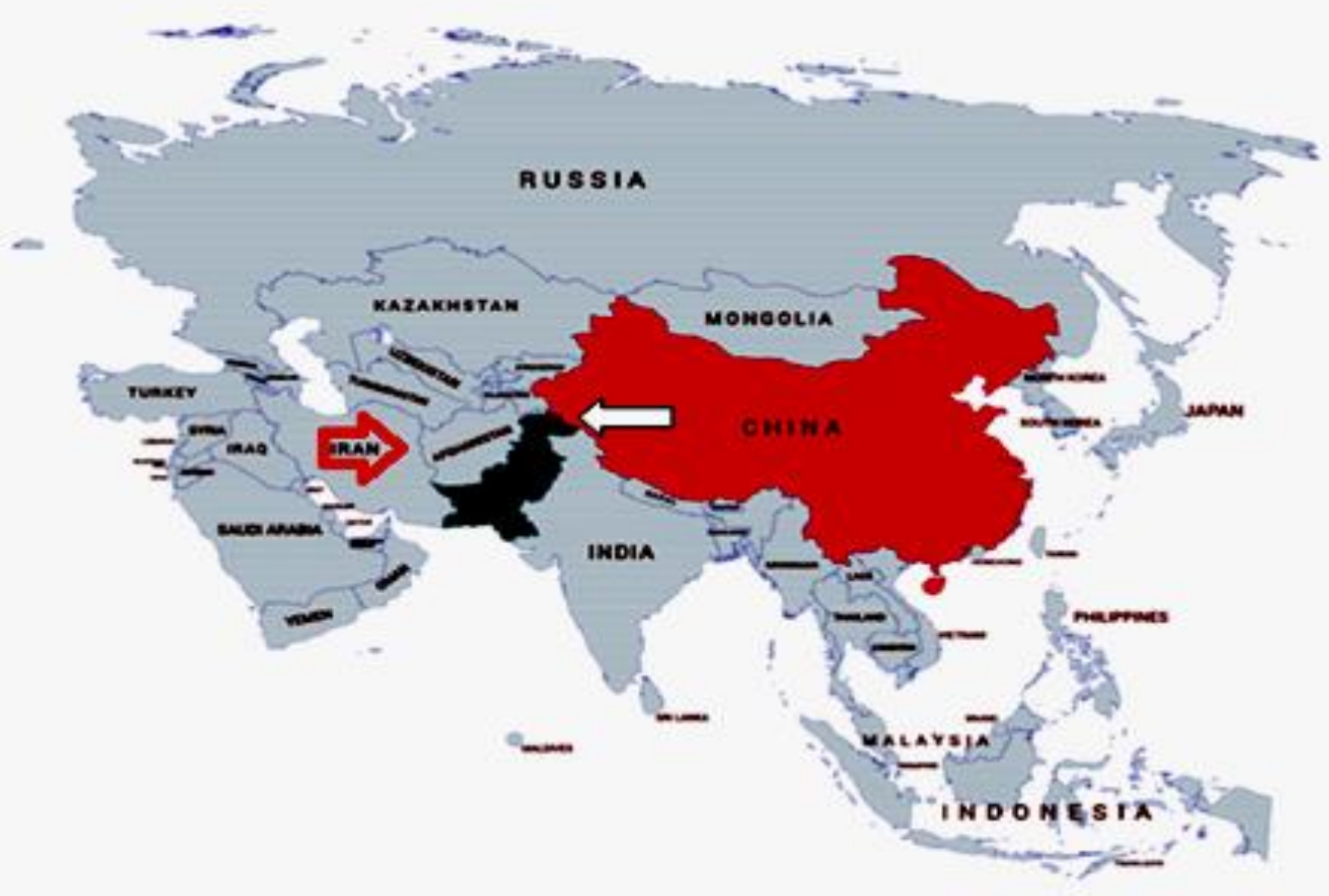

Figure 1. Map of Asian Countries showing border of Pakistan with China and Iran [Mapchart.net]

in China was at peak between late January and early days of February 2020 [14]. The epidemic was substantially decreased in early March 2020.

From China, COVID-19 jumped to other countries of the world by different modes especially through mass air travelling of people from China to allover the word. Till 9 May 2020, 4032763 cases of COVID-19 disease are reported globally with 276677 deaths [15]. USA has highest rate of infestation with 1322164 cases and 78616 deaths, Spain is second to USA with 262783 cases and 26478 deaths; and Italy with 217185 reported cases with 30201 causalities [16].

\section{COVID-19 IN PAKISTAN}

Pakistan is fifth populous country in the world with 212.2 million people according to World Health Organization. In spite of fairly well-developed infrastructure, it has poor health indicators with high mortality rate due to communicable and non-communicable diseases. Like lowand middle-income nations, Pakistan have many confronts in managing quality and reasonable health services for their citizens [17]. Pakistan has faced many outbreaks of infectious diseases and disaster in the past. As Pakistan has closed geographical association with China as shown in the Figure 1, the chance COVID-19 were more likely to hit Pakistan. As students and workers were moving back from China to Pakistan for winter break, it was the peak time of infestation. One such case has been reported on 24 January 2020 after a person traveled from China to Pakistan on 21 January 2020 via Dubai and was diagnosed for 2019-nCoV on 24 January [18]. However, the case was not officially reported by Government of Pakistan. After completion of the winter break in China, the movement of the Chinese workers abroad for their jobs has might be source of infestation in Pakistan and other countries as predicted by Tauseef et al. in 2020 [19].

The first patient of the COVID-19 disease was a student of University of Karchi, Sindh and second case was from federal territory [20]. These two students were recently return back from Iran. The first case of mortality due to coronavirus was reported in Mardan, Khyber Pakhtunkhwa. The travel history revealed that he has recently returned from Saudi Arabia. Majority of the infected people reported to return back from Iran, Saudi Arabia, China and United State.

\section{Current Situation of COVID-19 in Pakistan}

According to the ministry of Health, Pakistan, there are 27474 cases in the country with 618 mortalities and 7756 recoveries on Saturday, 9 May 2020 [21]. The highest rate of infection was appeared in Punjab (10471), followed Sindh (9691), Khyber Pakhtunkhwa (4327), Baluchistan (1876), Islamabad (609), and Gilgat Biltistan (421) (Figure 2). Initially, the rate of infection was reported high in Sindh province due to lack of testing facilities and quarantine for travelers who recently returned from Iran through Taftan boarder by land crossing. As Iran is highly affected with COVID-19, the chance of infestation was increased in Pakistan. 


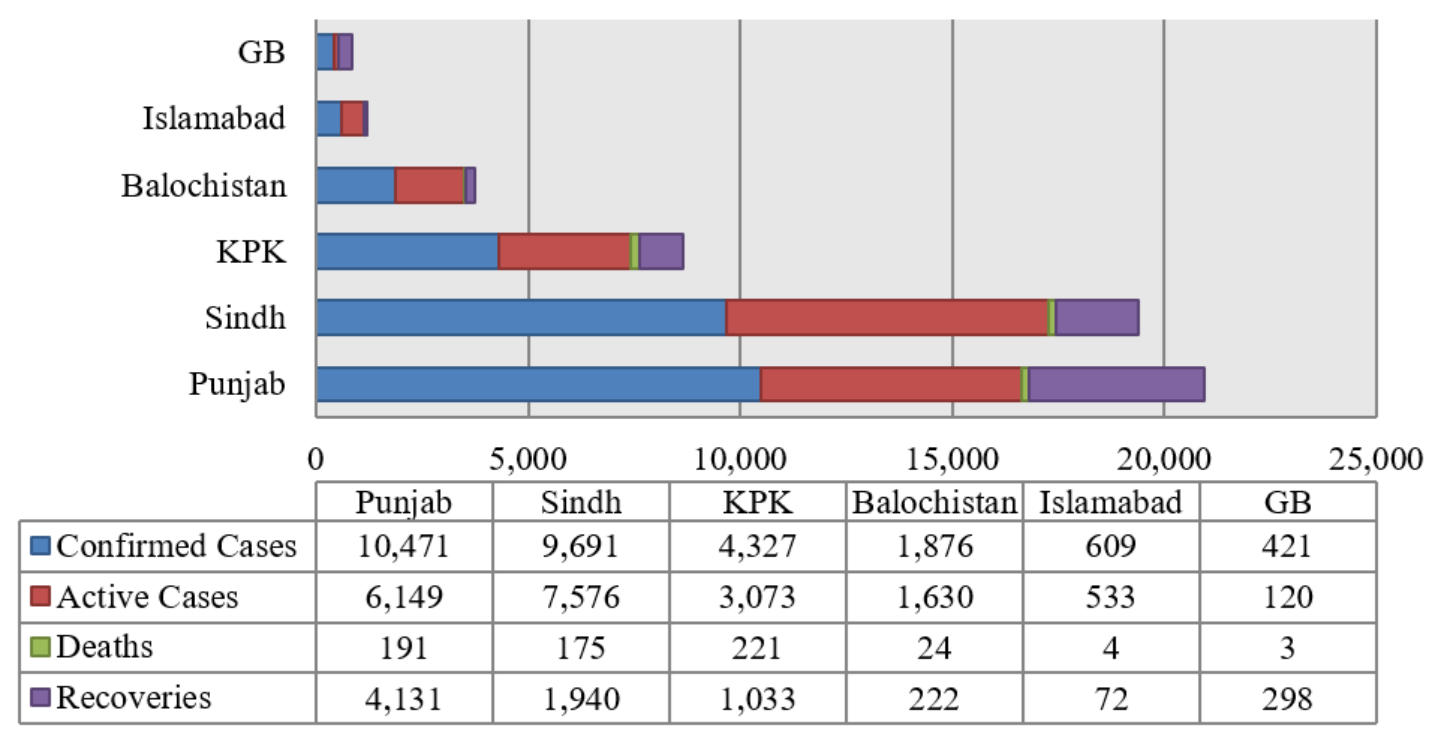

Figure 2. Recoveries vs. Deaths in Pakistan by COVID-19 till May 9,2020

\section{No of Hospitals for Covid-19}

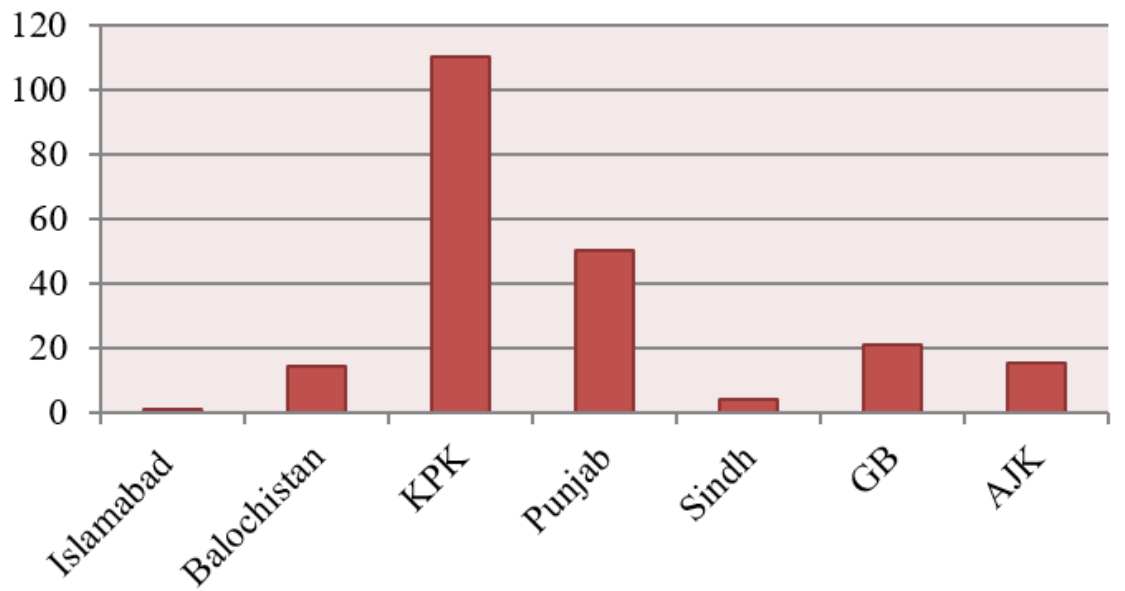

Province

Figure 3. No. of Designated Tertiary hospitals for Covid-19 in Pakistan

\section{Facilitation by Government of Pakistan against COVID-19}

The Government of Pakistan is taking all the measures against the COVID-19 to provide and insure the responsibilities of the state for their people. Since the first day when the first case was conformed in Karachi, Sindh, all the services and measures were used with the extreme capabilities to ensure the safeness of life in the region.

\section{COVID-19 Designated Tertiary Hospitals in Pakistan}

The nominations of the separate hospitals with advance and immediate diagnostic facilities for COVID-19 for a good gesture by the Government of the Pakistan. Province wise nominated hospitals were well equipped with diagnosis and isolation facilities to cope with outbreak of COVID-19. In federal territory of the Islamabad, only one hospital was nominated for COVID-19. Baluchistan have 10 hospital for COVID-19, Khyber Pakhtunkhwa (KPK) 7, Punjab 6, Sindh and Gilgit-Baltistan (GB) 4, and Azad Jammu and Kashmir (AJK) 3 nominated hospital for covid-19 as shown in Figure 3.

\section{Province Wise Hospitals with Isolation Facilities}

District wise isolation facilities were provided by the Government of Pakistan to prevent the spread of the COVID-19 infection to other patients in the hospitals. Punjab has highest isolation facility in 34 districts with 955 bed capacity. In the province of Khyber Pakhtunkhwa 110 function medical facilities with 856 beds capacity is available in 33 districts. The province of the Baluchistan has 14 isolation medical facilities with 534 accommodations of beds. Similarly, Gilgit Biltistan has 21, Azad Jammu and Kashmir 15, Sindh 4, and Islamabad has only 1 isolation medical facility. The province wise details of the medical isolation facility are shown in the Figure 4. 


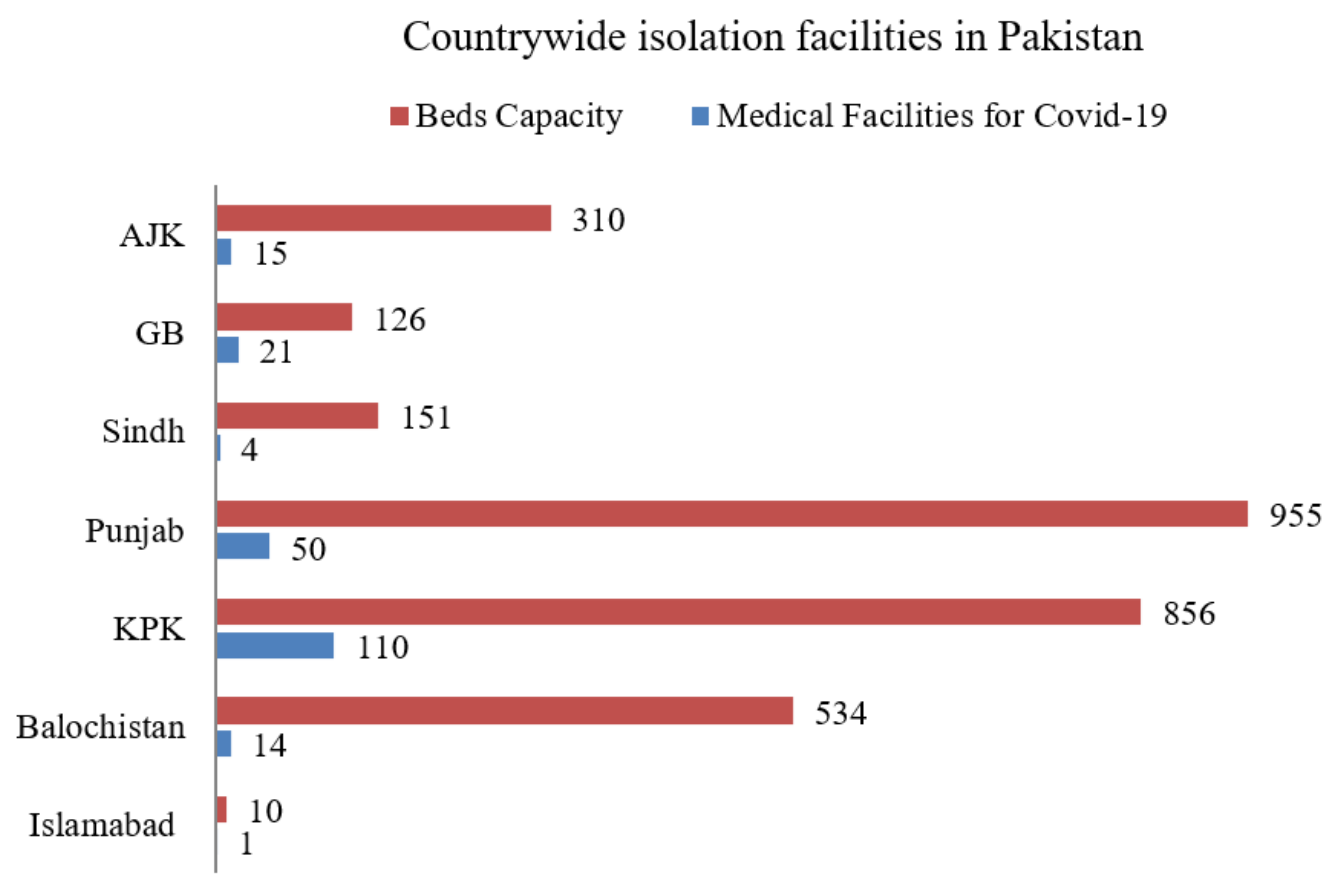

Figure 4. Countrywide isolation facilities for COVID-19 in Pakistan

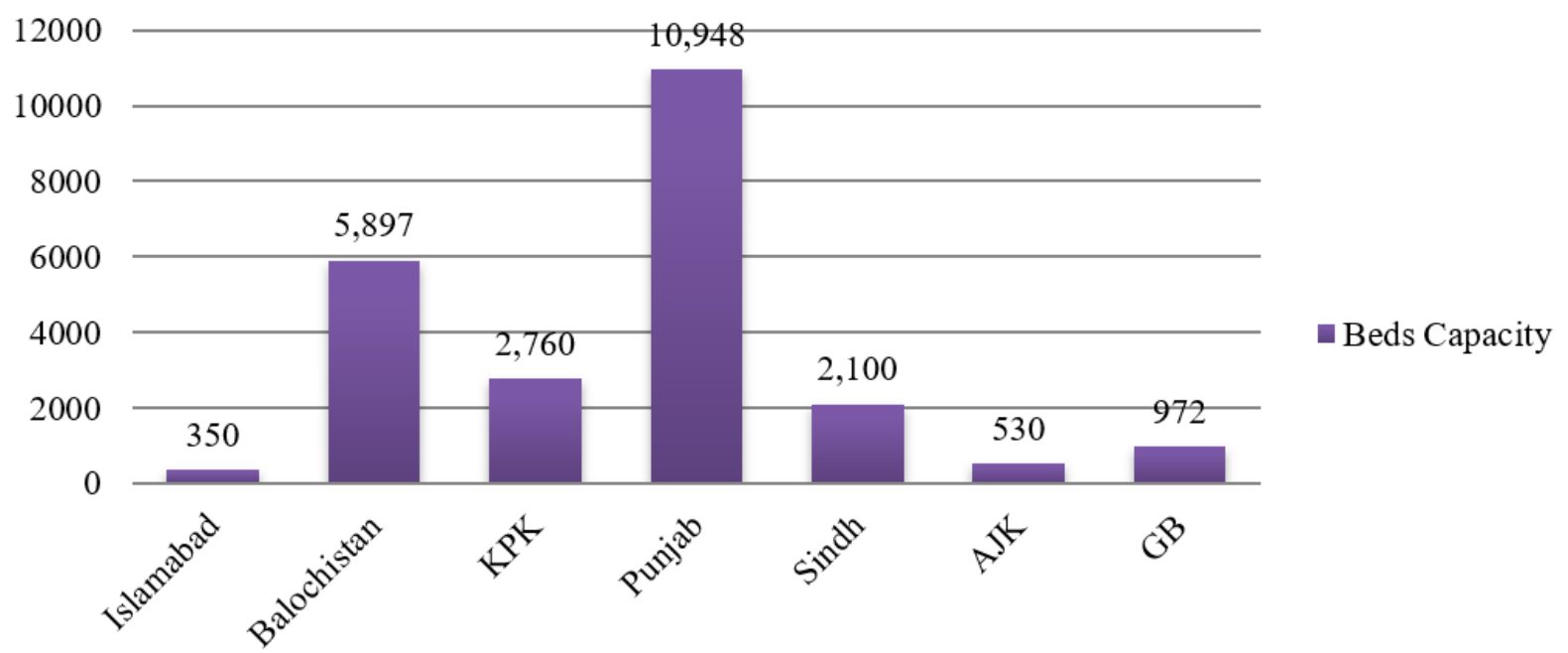

Figure 5. Province-Wise Quarantine Facilities for COVID-19 in Pakistan

\section{Establishment of Province-Wise Quarantine Facilities for Covid-19 \\ Seeking the demand of the time for coronavirus disease, establishment of the quarantine sites were developed for the suspects of COVID-19 with objective of monitoring of symptoms. Wide range of quarantine sites are distributed throughout the country (Figure 5).}

\section{COVID-19 Testing Facilities in Pakistan}

Like international method of COVID-19 diagnosis, Pakistan also employed PCR method of diagnosis of SARSCoV-2. World Health Organization has facilitated Pakistan with 15 testing machines and 15000 diagnostic kits to fight against COVID-19 infection [22]. Similarly, China has also donated 56000 testing kits to Sindh Government [23]. Now, Pakistan has wide range of province wise COVID-19 diagnostic capability. In different cities across the country 15 [ICT-01, Balochistan-01, KP-01, Punjab-04, Sindh-05, AJK01, GB-01 and NIH mobile testing lab deployed in Taftan] laboratories have been equipped with free PCR system facilities for COVID-19 test. Pakistan's testing capacity has been increased from 30,000 to 280,000 and would be further enhanced to 900,000 (Figure 6).

ISSUES AND CONCERNS OF COVID-19 IN
PAKISTAN
Shortage of Diagnostic Facilities for COVID-19
Due to lack of recourses for screening and diagnosis,
Pakistan was not fully prepared to fight against COVID-19.
As China and Iran were most affected neighboring countries
sharing border with Pakistan, the chance of COVID-19


Daily Testing Capacity of COVID-19 in Pakistan

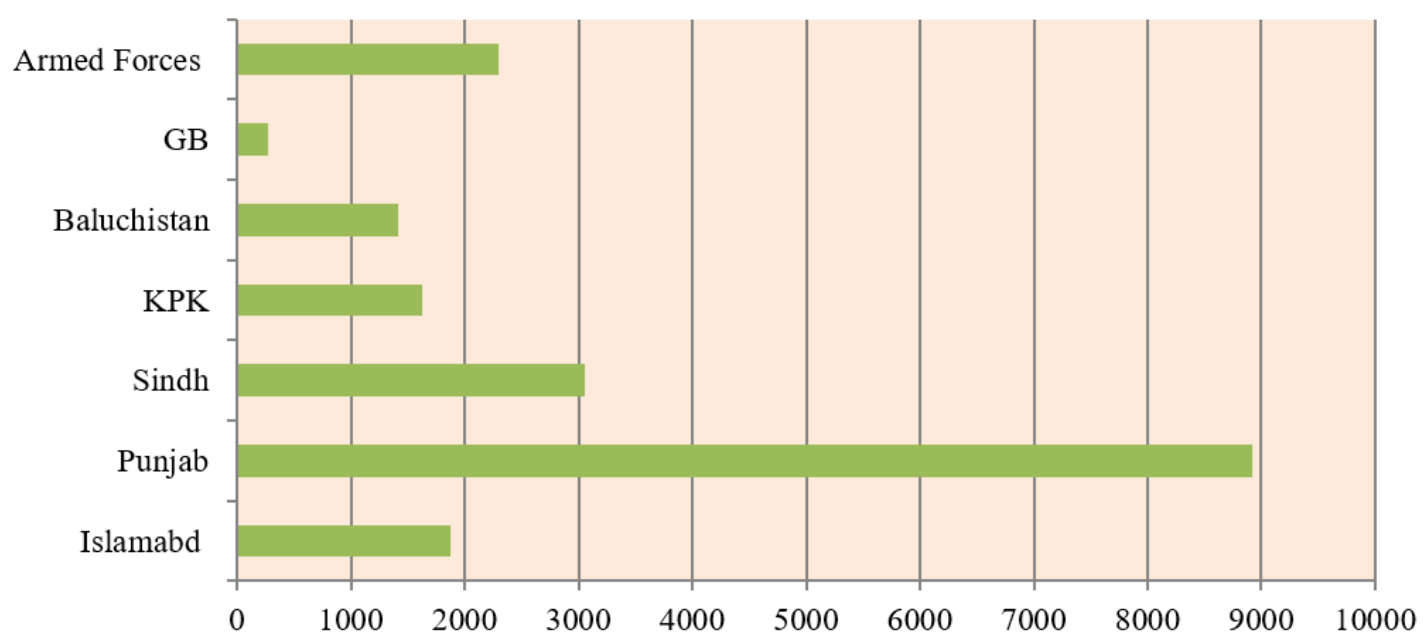

Figure 6. Daily testing capacities of different hospitals in Pakistan

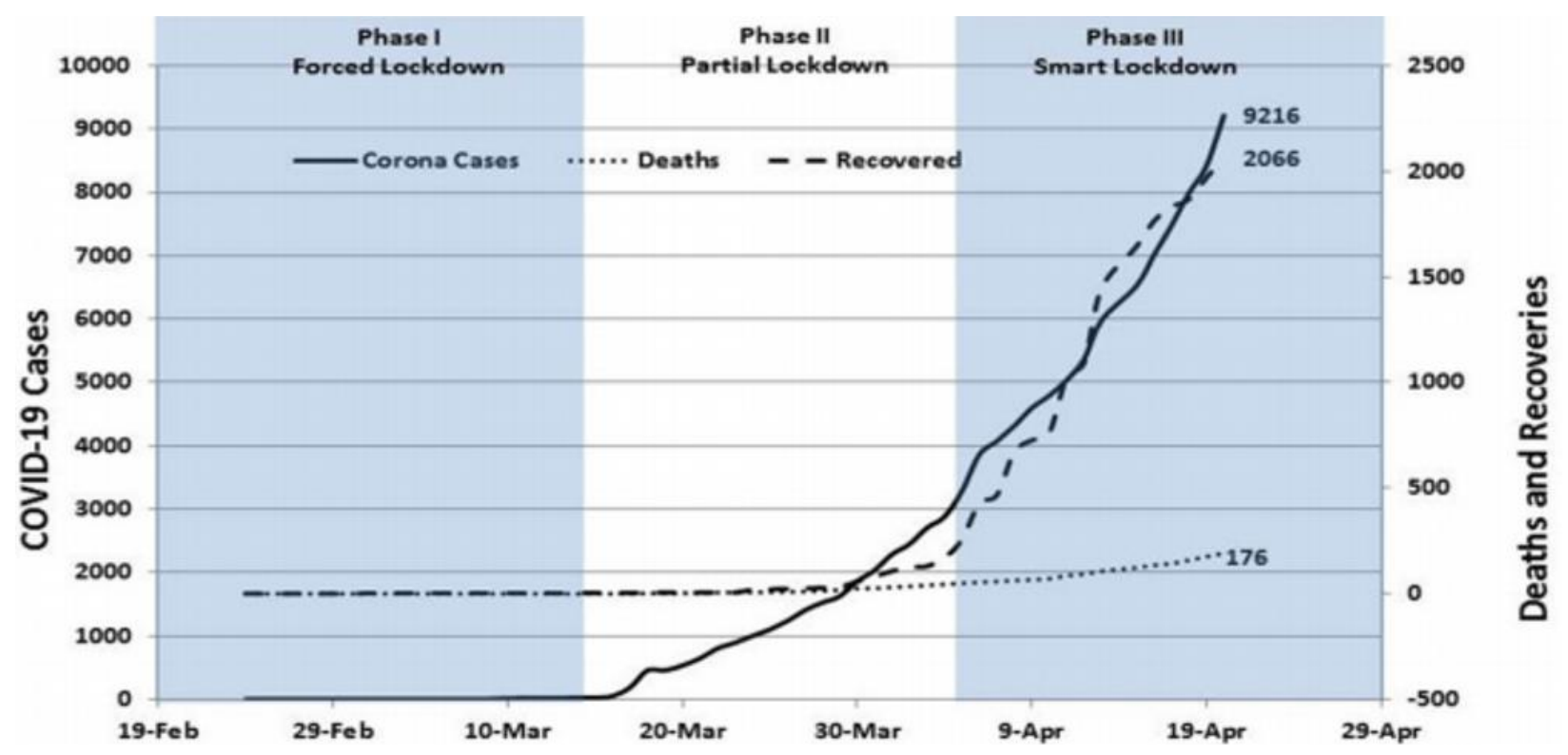

Figure 7. No. of COVID-19 cases in different lockdowns in Pakistan

infection was most probable due to frequent movement of people between these countries for trade and religious affairs.

Only Thermal Screening of the Pilgrims Returning from Saudi Arabia

The infection spread was more likely to occur due to returning of mass public from all over the world especially from China and Saudi Arabia in Pakistan. Airports were not fully equipped to screen the infected people and no quarantine sites were established at early outbreak.

\section{Mishandling of Shiite Pilgrims at Taftan Border}

A majority of COVID-19 infections in Pakistan are of pilgrims who returned to Pakistan from Iran earlier this month. The Baluchistan provincial government "quarantined" them at Taftan border with Iran; however, they were not properly managed by the authorities.

\section{FUTURE OF COVID-19 IN PAKISTAN}

World Health Organization has warned Pakistan that if effective innervations are not taken, the cases of COVID-19 may rise up to 200000 in the mid of July 2020. The expectations of WHO about COVID-19 in Pakistan may prove true if lockdown move towards smart lockdown or partial lockdown. Figure 7 clearly shows that the cases of the COVID-19 in Pakistan were very low owing to forced locked down in first phase. The partial lock down of the phase II and smart lockdown of the phase III has contributed a significant rise in the COVID-19 cases. What may contribute in making the WHO prediction true?

1. Partial or smart lockdown may contribute the spread of COVID-19 infection.

2. Non serious attitude of the general public towards the COVID-19 due to lack of awareness. 


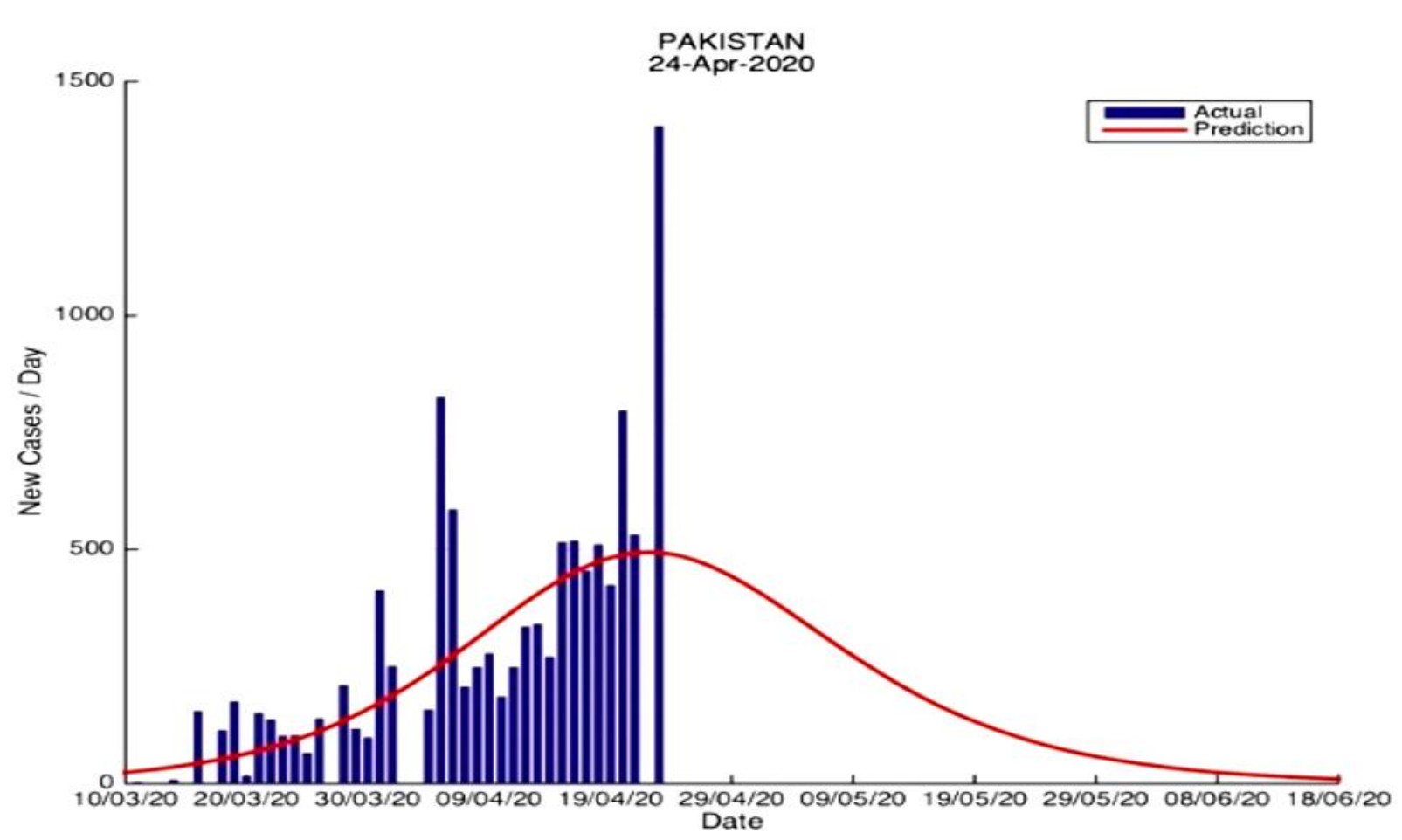

Figure 8. Ending Date of COVID-19 as predicted by Singapore University of Technology and Design

3. Mass gathering at different places.

4. Ignorance of the precautionary measurements like wearing of mask, use of sanitizer, free movement and hiding information of the infection.

\section{EXPECTED DATE OF ENDING OF COVID-19 IN \\ PAKISTAN}

The Singapore University Technology and Design has predicted ending dates of COVID-19 using mathematical modeling. According to this prediction, COVID-19 will end around 3 June 2020 from Pakistan. This also deepens whether, the standard operational procedures of prevention and quarantine is followed or not (Figure 8).

\section{CONCLUSIONS AND RECOMMENDATIONS}

SARS-CoV-2 originated from Wuhan City local sea food market and rapidly spread to 209 countries. No drug has been approved for Coronavirus disease by FDA, strict precautionary measurements of World Health Organization is required to be implemented for further transmission of COVID-19. Due to scarcity of the recourses in Pakistan like other developing countries, safe handling of COVID-19 was not expected in Pakistan. The various developments revealed that the control over COVID-19 were promising. Therefore, the various acts of Pakistan were appreciable and got control over the spread of COVID-19 to a big extent.

But, still there is certain facility gaps which if not immediately addressed would soon become havoc. Firstly, diagnostic facility is not easily available in the developing countries, strong need of cheap SARS-CoV-2 detection kits availability should be ensured as PCR based testing is costly. Massive awareness programmes for prevention of COVID-
19 for general public should be initiated. China remedial plans in controlling COVID-19 may also be followed in other countries. Furthermore, forced lockdown is also highly recommended for the effective control of COVID-19.

\section{ACKNOWLEDGEMENTS}

All the authors acknowledge and thank their respective Institutes and Universities.

Declaration of interest: The authors report no conflicts of interest.

Financial Disclosure: No financial support was received.

\section{REFERENCES}

1. Munster VJ, Koopmans M, van Doremalen N, van Riel $\mathrm{D}$, de Wit E. A novel coronavirus emerging in Chinakey questions for impact assessment. New England Journal of Medicine. 2020 Feb 20;382(8):692-4. doi: 10.1056/NEJMp2000929.

2. Yang D, Leibowitz JL. The structure and functions of coronavirus genomic 3 ' and 5' ends. Virus research. 2015 Aug 3;206:120-33. doi: 10.1016/j. virusres.2015.02.025.

3. Paules CI, Marston HD, Fauci AS. Coronavirus infections-more than just the common cold. JAMA. 2020 Feb 25;323(8):707-8. doi: 10.1001/jama.2020.0757.

4. Zhou F, Yu T, Du R, Fan G, Liu Y, Liu Z, Xiang J, Wang Y, Song B, Gu X, Guan L. Clinical course and risk factors for mortality of adult in patients with COVID-19 in Wuhan, China: a retrospective cohort study. The lancet. 2020 Mar 11. doi: 10.1016/S0140-6736[20]30566-3. 
5. Wang D, Hu B, Hu C, Zhu F, Liu X, Zhang J, Wang B, Xiang $\mathrm{H}$, Cheng $\mathrm{Z}$, Xiong $\mathrm{Y}$, Zhao Y. Clinical characteristics of 138 hospitalized patients with 2019 novel coronavirus-infected pneumonia in Wuhan, China. Jama. 2020 Mar 17;323(11):1061-9. doi: 10.1001/jama.2020.1585.

6. Gorbalenya AE. Severe acute respiratory syndromerelated coronavirus-The species and its viruses, a statement of the Coronavirus Study Group. BioRxiv. 2020 Jan 1. doi: 10.1101/2020.02.07.937862.

7. Deng SQ, Peng HJ. Characteristics of and public health responses to the coronavirus disease 2019 outbreak in China. Journal of clinical medicine. 2020 Feb;9(2):575. doi: $10.3390 /$ jcm 9020575 .

8. Dhama K, Sharun K, Tiwari R, Sircar S, Bhat S, Malik YS, Singh KP, Chaicumpa W, Bonilla-Aldana DK, Rodriguez-Morales AJ. Coronavirus disease 2019COVID-19. doi: 10.20944/preprints202003.0001.v1.

9. Ramadan N, Shaib H. Middle East respiratory syndrome coronavirus (MERS-CoV): A review. Germs. 2019 Mar;9(1):35. doi: 10.18683/germs.2019.1155.

10. Report of the WHO-China Joint Mission on Coronavirus DIsease 2019 [COVID-2019]. February 1624, 2020. Available at: http://www.who.int/docs/defaultsource/coronaviruse/who-china-joint-mission-oncovid-19-final-report.pdf (Accessed: 4 March 2020).

11. Rodriguez-Morales A, Tiwari R, Sah R, Dhama K. COVID-19, an emerging coronavirus infection: current scenario and recent developments-an overview. J. Pure Appl. Microbiol. 2020 Mar 1;14(1):6150. doi: 10.22207/JPAM.14.1.02.

12. Li Q, Guan X, Wu P, Wang X, Zhou L, Tong Y, Ren R, Leung KS, Lau EH, Wong JY, Xing X. Early transmission dynamics in Wuhan, China, of novel coronavirusinfected pneumonia. New England Journal of Medicine. 2020 Jan 29. doi: 10.1056/NEJMoa2001316.

13. Liu SL, Saif L. Emerging viruses without borders: the Wuhan coronavirus. doi: 10.3390/v12020130.
14. World Health Organization Director-General's opening remarks at the media briefing on COVID-19 - 24 February 2020. Available at: https://www.who.int/dg/ speeches/detail/who-director-general-s-openingremarks-at-the-media-briefing-on-covid-19---24february-2020 (Accessed: 26 February 2020).

15. worldometers.info. COVID-19 Coronavirus Pandemic. Available at: https://www.worldometers.info/ coronavirus/ (Accessed: 9 May 2020).

16. WMHC. Wuhan Municipal Health and Health Commission's Briefing on the Current Pneumonia Epidemic Situation in Our City. 2020. Available at: http://wjw.wuhan.gov.cn/front/web/showDetail/201912 3108989 (Accessed: 1 February 2020).

17. Lewis T, Synowiec C, Lagomarsino G, Schweitzer J. Ehealth in low-and middle-income countries: findings from the Center for Health Market Innovations. Bulletin of the World Health Organization. 2012;90:332-40. doi: 10.2471/BLT.11.099820.

18. ARY News. Available at: https://arynews.tv/en/firstcoronavirus-case-diagnosed-in-Pakistan/ (Accessed: 25 January 2020).

19. Ahmad T, Khan M, Khan FM, Hui J. Are we ready for the new fatal Coronavirus: scenario of Pakistan? Human Vaccines \& Immunotherapeutics. 2020 Mar 3;16(3):7368. doi: 10.1080/21645515.2020.1724000.

20. Gul A. Pakistan Detects First Coronavirus Cases, Links to Iran Outbreak. 26 February 2020. Available at: https://www.voanews.com/science-health/coronavirusoutbreak/pakistan-detects-first-coronavirus-caseslinks-iran-outbreak (Accessed: 20 March 2020).

21. Government of Pakistan. Realtime Pakistan and Worldwide COVID-19 situation. Available at: http://www.covid.gov.pk/ (Accessed: 9 May 2020).

22. The Nation. Available at: https://nation.com.pk/ (Accessed: 20 April 2020).

23. Staff Reporter. Sindh governor receives Chinese donation of 56,000 Covid-19 testing kits. Available at: https://www.dawn.com/news/1544296 